\title{
Perception of Palestinian Undergraduate Nursing and Midwifery Students About Professional Values: A Cross-Sectional Study
}

\author{
Mysoon Abu-El-Noor ${ }^{1}$, Rabia S Allari ${ }^{2}$ and Nasser Abu-El-Noor ${ }^{3 *}$ \\ ${ }^{1}$ Associate professor, Faculty of Nursing, Islamic University of Gaza, Gaza, P.O. Box 108, Palestine \\ ${ }^{2}$ Assistant Professor, Al-Ahliyya Amman University, Alsult, Jordan \\ ${ }^{3}$ Professor, Faculty of Nursing, Islamic University of Gaza, Gaza, P.O. Box 108, Palestine
}

*Corresponding author: Nasser Abu-El-Noor, Professor, Faculty of Nursing, Islamic University of Gaza, Gaza, P.O. Box 108, Palestine

\section{ARTICLE INFO}

Received: 㓞 July 30, 2021

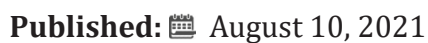

Citation: Mysoon Abu-El-Noor, Rabia S Allari, Nasser Abu-El-Noor. Perception of Palestinian Undergraduate Nursing and Midwifery Students About Professional Values: A Cross-Sectional Study. Biomed J Sci \& Tech Res 38(1)-2021. BJSTR. MS.ID.006085.

Keywords: Professional Nursing Values; Undergraduate Nursing Students; Undergraduate Midwifery Students; Perception; Gaza; Palestine

Abbreviations: NPV: Nursing Professional Values; NPVS: Nurses Professional Values Scale; ANA: American Nurses Association; SPSS: Statistical Package for Social Science; ANOVA: Analysis of variance

\section{ABSTRACT}

Background: Professional values provide a context for appraising beliefs and attitudes that guide behaviors and considered as standards for acceptable actions by professionals toward providing safe patient care.

Aim: This study aimed to assess professional values among Palestinian undergraduate nursing and midwifery students and examine the relationship between students' demographics and professional values.

Materials and Methods: A cross-sectional design was used in this study. A convenient sample of 370 undergraduate nursing and midwifery students from the Islamic University of Gaza, Palestine completed an electronic version of the revised nursing professional values scale, which consists of 26 items covering five domains (caring, trust, justice, activism and professionalism).

Results: Age of participants ranged between 18 and 36 years with a mean of 21.1 years. The majority of them were females $(60.7 \%)$, regular students $(87.3 \%)$, were enrolled in the nursing program (95.4\%). The top caring statement rated by the participants was "Maintain confidentiality of patient" (4.41) while the statement "Protect rights of participants in research" received the lowest score (3.62). The mean total scores of the domains of revised nursing professional values scale ranged between 3.610 for the "professionalism" domain and 4.133 for the "justice" domain. The variables related to age, gender, grades cumulative average, study year did not impact the scores of the revised nursing professional values scale or its domains.

Conclusion: This study found that professional values were relatively high among Palestinian nursing and midwifery students. Justice and caring domains were rated highest by participants, while activism and professionalism domains were rated low. These results should alert nursing educators to their roles in improving these values among nursing and midwifery students. This could be approached by empowering, role modeling and engagement of students in more activities to enhance these values.

\section{Introduction}

Professional values provide a context for appraising beliefs and attitudes that guide behaviors and considered as standards for acceptable actions by professionals [1]. Values are essential to the nursing practice, determining priorities and creating the relationships with clients. Specific values have been known as needed to professional nursing practice and should be considered 
vital in any baccalaureate nursing program [2]. Nurses around the world follow a shared set of professional values butterminology may differ, however basic principles of beliefs and attitudes are similar These professional values include respect for protection of client rights such as privacy, beneficence and non-maleficence, human dignity, responsibility and accountability [3]. In a qualitative study done by [4]. The participants' described a range of professional values and behaviors, but only four main professional values were identified, included: being person-centered; kindness and caring; being in control; and commitment to learning. Attaining Nursing Professional Values (NPV) is vital to professional development because of increasing quality of care; improve patient satisfaction, nurses job satisfaction and retention of staff [5]. Since such values are important and significant factors for quality care, so developing professional values among undergraduate nursing and midwifery students is central.

Worldwide, there have been a numerous studies in the issues of professional values. One was done by Parandeh, Khaghanizade, Mohammadi, and Nouri (2015) aimed to assess factors influencing development of professional values among nursing students and instructors. Researchers found that there is an influence of many elements such as individual, culture and education on developing nurses' professional values; in accordance, nursing programs should reflect that on the curriculum through valuebased cares and in clinical training [6]. Another study explored nursing students' perception of NPV and compared the NPV scores between participants according to demographic characteristics in South Korea [7]. The NPV scores were significantly higher in students who entered nursing schools following their desire and students who were planning to pursue graduate study than in those who entered because of their scores are sufficient and had not yet decided their career future. The NPV scores were not correlated with academic year, gender, or academic performance [8]. Moreover, in a study aimed to assess the perspective of nursing students from universities of medical sciences about professional values of nursing in Iran. The most important and least important items identified by the participants were the "maintain competency in area of practice "and "participate in peer review", respectively [9].

Regionally, a few studies conducted to assess nursing student's professional values, such as R. S. Allari, Ismaile, and Househ (2017) study to explore the perception of Saudi female nursing students on professional values and to examine the relationship between students' and their year of academic studies. The results presented that students have a positive perception of professional values in relation to confidentiality, privacy, patients' rights, safety, and work environment. Whereas they have a low perception engaging in professional nursing activities, evidence based practice, peer review, public policy, and participating in self-evaluation. And there was positive correlation between professional values and academic years [10]. The need to teach professionals with competencies that stand highly for the services that should be given to clients is becoming an issue of increasing importance. Nursing education and practice must be grounded on fixed high quality standards and competencies. The development of a nursing code of conduct is to guide nurses to make fitting clinical decision, when facing ethical dilemma.

It is significance that nurse educators, faculty members and instructors understand baccalaureate nursing students' perceptions of the importance of the code of conduct and the technical difficulties in implementing it though preparing them for future practice of nursing. According to the Palestinian Accreditation and Quality Assurance Commission (2014), the Code of Conduct includes the following principles: altruism, autonomy, human dignity, integrity, and social justice [11]. In accordance, one of the major nursing education standard or outcome in relation to professional values in higher education in Palestine is aimed that students and graduates should exhibit ethical behavior and understands and follow professional values. This outcome can be achieved by the help of nursing program who provides opportunities for students to participate in professional organizations that advocate for quality and health care, uses realistic scenarios for students that address ethical, and legal patient care situations, provides opportunities to participate in inter-professional service-learning projects, uses reflective writing as assessment strategy to discuss student perception of advocacy role and identifies the influence of his/her attitudes, values, on practice, develops a student honor code and professional values to be embraced, and demonstrates professionalism [12].

Palestinian nursing and midwifery students need to know that it is important to understand the nurses' professional values because they are in a specialty that carries great privilege and responsibilities. On the other hand, Palestinian cultural values are mostly generosity, selflessness, hospitality, and respect for relatives, willingness, chastity and sexual modesty. These values are greatly related in the essence to the professional values, so it will not be so demanding for Palestinian nursing and midwifery students to hold professional values. Nursing values is essential globally and locally. Therefore, educating nursing and midwifery students about the significance of nurses' values and the need to be committed to apply those values through their health care practices, and decision making thus will improve patients out comes. However, there were no papers about professional values among Palestinian undergraduate nursing and midwifery students. The purpose of this study is to assess professional values among Palestinian undergraduate nursing and midwifery students and examine the relationship between students' demographics and professional values. 


\section{Materials and Methods \\ Design, Setting and Sampling}

A cross-sectional, descriptive design was used in this study. The target population comprised of undergraduate nursing and midwifery students enrolled in the second semester at the Faculty of Nursing at the Islamic University of Gaza. This included students who are upgrading from associate degree to bachelor's degree. Data were collected after students had finished their final exams for the second semester. There were 1392 students enrolled in this semester, 920 of them were females and 412 males; 221 were enrolled in the midwifery department while the rest (1170) were in the nursing department. The sample size was calculated using sample size calculator Rao soft ${ }^{\circledR}$. With a population size 1392 , margin error $5 \%$, confidential level $95 \%$, distribution response $50 \%$ the recommended sample size given was 302 students, but all the population were targeted to compensate for missing responses and reach the intended sample size. A total of 370 students completed an electronic version of the questionnaire. Data were collected by electronic means due to the spread of COVID-19 pandemic. The link for the survey was sent to students through WhatsApp groups established by the faculty members to communicate with students during the COVID-19 pandemic.

\section{Instrument}

A self-administered electronic questionnaire was used in this study. The Nurses Professional Values Scale (NPVS) was developed by Schank and Weis (2000) to measure professional nursing values based on the American Nurses Association (ANA) Code of Ethics for Nurses [13]. The instrument was then revised by same authors and now is known as Nurses Professional Values Scale-Revised (NPVS-R) [14]. The NPVS-R is used to measure professional values and has been translated and validated into the Arabic language by R. Allari. The NPVS-R includes 26 items based on the nine provisions of the Code of Ethics for Nurses [15]. Each item of the NPVS-R contains expressive statement that reflects the interpretive statements of the Code of Ethics of the American Nurses Association. Each statement NPVS-R is rated on a five-point Likert scale. For each item, the possible answers are:
a) not important
b) slightly important
c) important
d) very important
e) most important

The NPVS-R was designed with five factors supported by psychometric evaluation done by Weis and Schank (2009).
Those factors were caring, activism, trust, professionalism, and justice. The Arabic version [16] was tested for the reliability and validity and the results revealed that the scale to be valid and highly reliable to be used for assessing PNV among Arab nursing students. Internal consistency reliability of the five factors were significantly high ranging from 0.71 to 0.91 . Internal consistency reliability reported from this study for NPVS-R was 0.950 and ranged between 0.766 and 0.899 for its domains.

\section{Data Analysis}

The Statistical Package for Social Science (SPSS), version 18, was used to compute and analyze the data. Data was analyzed using descriptive statistics (frequency, percentage, mean and standard deviation). Analysis of variance (ANOVA), t-test and Pearson's correlation coefficient were used to examine impact of study variables on professional values. Statistical significance was established at the 0.05 level.

\section{Ethical Considerations}

Prior to conducting this research study, ethical clearance was obtained from the Research Ethics Committee Board at the Islamic University of Gaza. Participants were informed about the purpose of the study at the opening statement of the electronic questionnaire and were assured that their participation is completely voluntary and that participant one has the right to refuse to complete the questionnaire. Participants were assured that if they decided to refuse to be involved in the study, this decision would not affect their grades. Data was collected anonymously from all participants. In the final report, confidentiality and anonymity will be maintained.

\section{Results}

\section{Characteristics of Participants}

A total of 370 nursing student completed the questionnaire. Table 1 represents the characteristics of participants. The majority of participants were females $(60.7 \%, \mathrm{n}=258)$. Age ranged between 18 and 36 years with a mean of 21.1 years $( \pm 2.78)$. The majority of participants were regular students $(87.3 \%, \mathrm{n}=323)$ while the rest were upgrading student from associate degree to a bachelor's degree. Most of the respondent were from student in the third year $(40.8 \%, \mathrm{n}=151)$ while the least were from students in the second year $(12.7 \%, n=47)$. The great majority of our participants $(95.4 \%$, $\mathrm{n}=353$ ) were enrolled in the nursing program while the rest came from the midwifery program. Grade accumulative average ranged between 50.2 and 98.4 with a mean of 79.51( \pm 7.7$)$. Finally, the great majority of participants $(83.2 \%, \mathrm{n}=308)$ were planning to study nursing at the time of enrollment. 
Table 1: Descriptive statistics for participants' characteristics.

\begin{tabular}{|c|c|c|c|}
\hline \multicolumn{2}{|c|}{ Variable } & \multirow{2}{*}{$\begin{array}{c}\text { Frequency } \\
112 \\
\end{array}$} & \multirow{2}{*}{$\begin{array}{c}\% \\
30.3 \\
\end{array}$} \\
\hline Cond & Male & & \\
\hline Genaer & Female & 258 & 60.7 \\
\hline \multirow{2}{*}{ Type of enrolment } & Regular student & 323 & 87.3 \\
\hline & Upgrading student & 47 & 12.7 \\
\hline \multirow{4}{*}{ Year of study } & First year & 73 & 19.7 \\
\hline & Second year & 47 & 12.7 \\
\hline & Third year & 151 & 40.8 \\
\hline & Fourth year & 99 & 26.8 \\
\hline \multirow{2}{*}{ Department } & General nursing & 353 & 95.4 \\
\hline & Midwifery & 17 & 4.6 \\
\hline \multirow{3}{*}{$\begin{array}{c}\text { Did you plan to study nursing at } \\
\text { time of enrolment }\end{array}$} & Yes & 308 & 83.2 \\
\hline & No & 42 & 11.4 \\
\hline & I don't know & 20 & 5.4 \\
\hline Age & \multicolumn{3}{|c|}{ Min: 18 Max: 36 Mean: 21.1 SD: 2.78} \\
\hline Grade accumulative average & \multicolumn{3}{|c|}{ Min: 50.2 Max: 98.4 Mean: 79.51 SD: 7.7} \\
\hline
\end{tabular}

\section{NPVS-R and its Dimensions}

The total score for the NPVS-R ranged from 26 and 130 with a mean of $100.68( \pm 16.55)$. Table 2 depicts the number of items, minimum, maximum, total score, standard deviation and mean for the NPVS-R and its subdomains. This is beside the Chronbach's alpha for each of them. Chronbach's alpha for the NPVS-R was 0.95 and for the subdomains, they ranged between 0.766 and.899; which all fall within the acceptable ranges. The domain Justice was ranked first by our participants with a mean of 4.133 while the professionalism domain received the lowest mean (3.610). The top caring factor statement rated by the participants was "Maintain confidentiality of patient" with a mean of $4.41( \pm 0.86)$ followed by "Safeguard patient's right of privacy". On the other hand, participants rated "Protect rights of participants in research" as the lowest statement with a mean of $3.62( \pm 1.04)$ (Table 3$)$. The statement "Advance the profession through active involvement in health related activities" received the highest mean among the activism domain with a mean of $4.07( \pm 0.96)$. Moreover, the statement "Participate in public policy decisions affecting distribution of resources" received the least score with a mean of $2.94( \pm 1.04)$ (Table 4).

Table 2: Descriptive statistics for NPVS-R and its domains.

\begin{tabular}{|c|c|c|c|c|c|c|c|}
\hline Domain & $\begin{array}{c}\text { Number of } \\
\text { items }\end{array}$ & Min. score & Max. score & Total Score & Std. Dev. & $\begin{array}{c}\text { Chronbach's } \\
\text { alpha }\end{array}$ \\
\hline Total score & 26 & 26.00 & 130.00 & 100.68 & 16.55 & 3.872 & 0.950 \\
\hline Caring & 9 & 9.00 & 45.00 & 36.10 & 6.35 & 4.011 & 0.899 \\
\hline Activism & 5 & 5.00 & 25.00 & 18.08 & 3.70 & 3.616 & 0.800 \\
\hline Trust & 5 & 5.00 & 25.00 & 19.66 & 3.28 & 3.932 & 0.766 \\
\hline Professionalism & 4 & 4.00 & 20.00 & 14.44 & 2.98 & 3.610 & 0.768 \\
\hline Justice & 3 & 3.00 & 15.00 & 12.40 & 2.27 & 4.133 & 0.799 \\
\hline
\end{tabular}

Table 3: Mean and ranking of statements of caring dimension.

\begin{tabular}{|c|c|c|c|c|}
\hline Rank & Item No. & Statement & Mean & SD \\
\hline 1 & 25 & Maintain confidentiality of patient & 4.41 & 0.86 \\
\hline 2 & 21 & Safeguard patient's right to privacy & 4.40 & 0.79 \\
\hline 3 & 16 & Protect moral and legal rights of patients & 4.28 & 0.91 \\
\hline 4 & 24 & Practice guided by principles of fidelity and respect for person & 4.15 & 0.88 \\
\hline 5 & 18 & Act as a patient advocate & 3.93 & 1.03 \\
\hline 6 & 20 & Provide care without prejudice to patients of varying lifestyles & 3.87 & 0.96 \\
\hline 7 & 17 & Refuse to participate in care if in ethical opposition to own professional values. & 3.78 & 1.19 \\
\hline 8 & 22 & Confront practitioners with questionable or inappropriate practice & 3.66 & 1.02 \\
\hline 9 & 23 & Protect rights of participants in research & 3.62 & 1.04 \\
\hline
\end{tabular}


Table 4: Mean and ranking of statements of activism dimension.

\begin{tabular}{|c|c|c|c|c|}
\hline Rank & Item No. & Statement & Mean & SD \\
\hline 1 & 10 & Advance the profession through active involvement in health related activities & 4.07 & 0.96 \\
\hline 2 & 11 & Recognize role of professional nursing associations in shaping health care policy & 3.77 & .93 \\
\hline 3 & 26 & Participate in activities of professional nursing associations & 3.67 & 1.02 \\
\hline 4 & 19 & $\begin{array}{c}\text { Participate in nursing research and/or implement research findings appropriate to } \\
\text { practice }\end{array}$ & 3.64 & 1.00 \\
\hline 5 & 4 & Participate in public policy decisions affecting distribution of resources & 2.94 & 1.04 \\
\hline
\end{tabular}

Table 5 depicts the means for the trust dimension. The statement "Maintain competency in area of practice" received the highest rank with a mean of $4.20( \pm 0.89)$. Moreover, the statement "Engage in on-going self-evaluation" was ranked last with a mean of $3.49( \pm 0.89)$. Table 6 represents the means for the statements related to professionalism dimension. The means ranged between $4.13( \pm 0.92)$ for the "Initiate actions to improve environments

Table 5: Mean and ranking of statements of "Trust" dimension. of practice" statement and $2.88( \pm 1.06)$ for the "Participate in peer review" statement. Finally, the top statement rated by the participants in the justice dimensions was "Protect health and safety of the public" as it received a mean of $4.37( \pm 0.84)$. On the other hand, participants rated the statements of "Assume responsibility for meeting health needs of the culturally diverse population" as the lowest rated statement with a mean of $3.85( \pm 0.97)$ (Table 7).

\begin{tabular}{|c|c|c|c|c|}
\hline Rank & Item No. & Statement & Mean & SD \\
\hline 1 & 19 & Maintain competency in area of practice & 4.20 & 0.89 \\
\hline 2 & 9 & Seek additional education to update knowledge and skills & 4.02 & 0.93 \\
\hline 3 & 14 & Accept responsibility and accountability for own practice & 3.98 & 0.93 \\
\hline 4 & 2 & Request consultation/collaboration when unable to meet patient needs & 3.97 & 0.87 \\
\hline 5 & 1 & Engage in on-going self-evaluation & 3.49 & 0.89 \\
\hline
\end{tabular}

Table 6: Mean and ranking of statements of Professionalism dimension.

\begin{tabular}{|c|c|c|c|c|}
\hline Rank & Item No. & Statement & Mean & SD \\
\hline 1 & 8 & Initiate actions to improve environments of practice & 4.13 & 0.92 \\
\hline 2 & 7 & Promote and maintain standards where planned learning activities for students take & 3.76 & 0.92 \\
\hline 3 & 6 & place & 3.67 & 0.98 \\
\hline 4 & 5 & Establish standards as a guide for practice & 2.88 & 1.06 \\
\hline
\end{tabular}

Table 7: Mean and ranking of statements of Justice dimension.

\begin{tabular}{|c|c|c|c|c|}
\hline Rank & Item No. & Statement & Mean & SD \\
\hline 1 & 3 & Protect health and safety of the public & 4.37 & 0.84 \\
\hline 2 & 12 & Promote equitable access to nursing and health care & 4.18 & 0.90 \\
\hline 3 & 13 & Assume responsibility for meeting health needs of the culturally diverse population & 3.85 & 0.97 \\
\hline
\end{tabular}

\section{Influencing Factors on NPVS-R and its Subdomains}

Results of correlation coefficient revealed no significant correlation between age nor grades cumulative average and total score of NPVS-R and its domains. Results of t test showed that gender did not affect means of NPVS-R and its subdomains. On the other hand, when test for significance difference between regular student and upgrading students, it was found that there was a statistically significant difference between the means of the two groups in the domain of professionalism as the mean for regular students was 14.33 and for upgrading students $15.17(p=0.38)$. There was slight difference between the means of justice domain of nursing student (mean 12.6) and midwifery students (mean 13.39) with a $\mathrm{p}$ value of 0.48 . One way ANOVA did not show any difference in the means of NPVS-R and its subdomains among students from different levels of study.

While ANOVA test did not show any difference if the means of activism and justice subdomains according to students planning at enrolment time, there were some difference in the means of total score of NPVS-R and the other subdomains (Table 8). Differences were found to be statistically significant between the means of student who planned to enroll at the faculty of nursing and those who did not know in the total score of NPVS-R ( $p=0.033)$, trust domain $(p=0.039)$ and professionalism domain ( $p=0.038)$, while the significance in differences in the caring domain was due to the difference in the means of students who planned to enroll at the faculty of nursing and those who did not ( $p=0.023)$. 
Table 8: Descriptive statistics to NPVS-R and its domains in relation to the variable whether students plan to study nursing the time of enrollment.

\begin{tabular}{|c|c|c|c|c|}
\hline & & Mean & SD & $P$ value \\
\hline \multirow{3}{*}{ Total score } & Planned to enroll & 101.69 & 16.22 & 0.014 \\
\hline & Did not plan to enroll & 97.50 & 15.79 & \\
\hline & Did not know & 91.75 & 20.18 & \\
\hline \multirow{3}{*}{ Caring } & Planned to enroll & 36.47 & 6.19 & 0.013 \\
\hline & Did not plan to enroll & 35.14 & 6.13 & \\
\hline & Did not know & 32.45 & 8.12 & \\
\hline \multirow{3}{*}{ Trust } & Planned to enroll & 19.8 & 3.20 & 0.029 \\
\hline & Did not plan to enroll & 19.29 & 3.31 & \\
\hline & Did not know & 17.90 & 3.96 & \\
\hline \multirow{3}{*}{ Professionalism } & Planned to enroll & 14.60 & 2.95 & 0.21 \\
\hline & Did not plan to enroll & 13.98 & 2.74 & \\
\hline & Did not know & 12.85 & 3.45 & \\
\hline
\end{tabular}

\section{Discussion}

The present study aimed to assess professional values from the perception of undergraduate Palestinian nursing and midwifery students. The top caring factor statement rated by the participants was "Maintain confidentiality of patient" (4.41) while the statement "Protect rights of participants in research" received the lowest score (3.62). On the other hand, the mean total scores of the domains of PNV-R ranged between 3.610 for the "professionalism" domain and 4.133 for the "justice" domain. While the variables age, gender, grades cumulative average, study year did not impact the scores of PNV-R or its domains, results of upgrading students were higher in the domain of professionalism. Moreover, there was slight difference between the means of justice domain among nursing students (mean 12.6) and midwifery students (mean 13.39). The high scores of nursing professional values reported in this study are congruent with many other findings from other studies conducted in different countries [17-29]. The relatively high scores of NPVS-R reflects adherence of nursing programs to providing nursing and midwifery students the essential standards of preparing nursing and midwifery students for practice and support in their professional values [19]. This argument is supported by Sibandze and Scafide (2018) who found, in an extensive literature review, that nurses pursuing a Bachelor of Nursing had a more awareness and application of professional values than nurses with lower levels of academic or non-academic education.

Participants of this study rated "Justice" and "caring" as the highest domains of NPVS-R. Other studies ranked the domain "Justice" as the highest or the second highest domain [25]. The justice domain is considered the "basis for all professional interactions across all care settings" [26] and it reflects nurses' duty to provide equal care to all patients regardless of diversity issues [30]. A potential cause for rating "justice" as the highest domain by Palestinian nursing and midwifery students is the fact that Palestine is one of the few countries that are still under occupation, which enhances feelings of injustice among Palestinians; therefore, they do their best to provide justice for their clients. The second most important domain from participants' perception was "caring." This domain was rated as the first or second most important domain in many other studies [31]. Caring includes "having a concern or regard for that which affects the welfare (of another)" and it is considered central to nursing practice [32]. Furthermore, dimensions of caring are considered as the most fundamental values and commitments of the nurse in the ANA code of ethics [33]. Begum and Slavin (2012) argued that nurturing a caring attitude in nursing education is important as this is the first place for students to learn about the most significant values and essence of their profession.

Moreover, giving high scores by nursing participants to items related to "caring" dimension could be due to that caring is considered by students as the major role of nurses and the spirit of nursing practice. Another reason for rating high scores for the items of "caring" could be due to the fact that nursing programs may have an impact on students' caring values and behaviors and that students are evaluated in their practice mostly for their skills of caring during their practice. The statement "maintain confidentiality of patient" from the "caring" domain received the highest score of the NPVS-R items with a mean of 4.41 . This reflects the high attention students pay for safeguarding patients' rights for privacy and maintaining confidentiality, which are core competences of caring. This goes in line with other studies which ranked this item in the top items of the NPVS-R the caring domain. R. S. Allari considered the issue of maintaining privacy as an essential right since it is a part of the Islamic doctrine which is the main religion in Palestine and influencing the actions and cultural believes of the participants.

The low scores of our participants related to public policy, professional organizations and peer review is not unique to our 
results. Other studied reported similar results. This could be due to the political chaos that prevails in the region where people, including nurses and nursing and midwifery students, are not really involved in such activities. Finally, the scores of the domains "activism" and "professionalism" were rated with the lowest scores by our participants, which goes in line with other studies. These results should alert nursing educators to their roles in improving these values among nursing and midwifery students. This could be approached by empowering, role modeling and engagement of students in more activities to enhance these values. Moreover, faculties of nursing may help to enhance these values through arranging meetings and forums with faculty members, national nursing pioneers in research, activities in public policy and engaging students in peer reviews, self-evaluations, and lead professional nursing events and activities.

\section{Conclusion}

This study found that Palestinian nursing and midwifery students' perceptions of the importance of professional values were relatively high. Items related to justice and caring domains were rated highest by participants, while items related to activism and professionalism domains were rated low. While the variables age, gender, grades cumulative average, study year did not impact the scores of PNV-R or its domains, results of upgrading students were higher in the domain of professionalism and midwifery students reported slightly higher score in justice domain than nursing students. These results should alert nursing educators to their roles in improving these values among nursing and midwifery students. This could be approached by empowering, role modeling and engagement of students in more activities to enhance these values. Furthermore, nursing educator need to focus on enhancing facilitating factors which include personal factors (such as stimuli, believe in God, inner beliefs and acting on values) and environmental factors (such as cooperation, order and discipline) ensure avoiding inhibiting factors which include personal inhibitors (the lack of professional motivation and enthusiasm, negative emotions) and environmental inhibitors (unfavorable work environment, society's negative attitude toward nursing, the violation of rights).

\section{References}

1. Abdullah KL, Chong MC (2019) Factors influencing professional values among Indonesian undergraduate nursing students. Nurse education in practice 41: 102648 .

2. (2020) Accreditation and Quality Assurance Commission (2014). Standards for Baccalaureate Nursing Programs.

3. Allari R (2016) Nursing professional values scale: psychometric properties of Arabic version. Int J Recent Scientific Research 7(9): $13240-13244$.

4. Allari RS (2020) Nursing as a profession: Undergraduate female students' perception. TMR Integrative Nursing 4(2): 65-72.

5. Allari RS, Ismaile S, Househ M (2017) Professional values among female nursing students in Saudi Arabia. Informatics Empowers Healthcare Transformation 238: 231-234.
6. (1985) American Nurses Association. Code for nurses with interpretive statements. Washington, DC: ANA Publishing.

7. (2001) American Nurses Association. Code of Ethics for Nurses with Interpretive Statements.

8. Bang KS, Kang JH, Jun MH, Kim HS, Son HM (2011) Professional values in Korean undergraduate nursing students. Nurse education today 31(1): 72-75.

9. Begum S, Slavin H (2012) Perceptions of "caring" in nursing education by Pakistani nursing students: An exploratory study. Nurse education today 32(3): 332-336.

10. Bijani M, Tehranineshat B, Torabizadeh C (2019) Nurses', nursing students', and nursing instructors' perceptions of professional values: a comparative study. Nursing ethics 26(3): 870-883

11. Bleda S, Alvarez I, Prat M (2020) The Perceptions of Professional Values among Students at a Spanish Nursing School. Paper presented at the Healthcare 8(2): 74

12. Clark DK (2009) Professional values: a study of education and experience in nursing students and nurses. Capella University.

13. Donmez RO, Ozsoy S (2016) Factors influencing development of professional values among nursing students. Pakistan journal of medical sciences 32(4): 988

14. Fisher M (2014) A comparison of professional value development among pre-licensure nursing students in associate degree, diploma, and Bachelor of Science in nursing programs. Nursing education perspectives 35(1): 37-42.

15. Horton K, Tschudin V, Forget A (2007) The value of nursing: a literature review. Nursing ethics 14(6): 716-740.

16. Jasemi M, Cheraghi R, Azimzadeh R, Namadi F (2020) The relationship between personality characteristics and adherence to professional values among nursing students. Nursing and Midwifery Studies 9(1): 29.

17. Kobra P, Vahid Z, Alsadat HF (2012) Nursing students' perspectives on professional values in the universities of medical sciences in Iran. International Research Journal of Applied and Basic Sciences 3(6): 1183-1191.

18. Lin YH, Wang LS (2010) A Chinese version of the revised nurse's professional values scale: Reliability and validity assessment. Nurse education today 30(6): 492-498.

19. Lyneham J, Levett Jones T (2016) Insights into Registered Nurses' professional values through the eyes of graduating students. Nurse education in practice 17: 86-90.

20. Manninen E (1998) Changes in nursing students' perceptions of nursing as they progress through their education. Journal of Advanced Nursing 27(2): 390-398

21. Moon S, Kim DH, Kim EJ, Kim YJ, Lee S (2014) Evaluation of the validity and reliability of the Korean version of the Nursing Professional Values Scale-Revised. Nurse education today 34(3): 325-330.

22. Ozyazicioglu N, Surenler S (2018) Determination of professional values in nursing students. International Journal of Caring Sciences 11(1): 254.

23. Parandeh A, Khaghanizade M, Mohammadi E, Nouri JM (2015) Factors influencing development of professional values among nursing students and instructors: a systematic review. Global journal of health science $7(2): 284-293$.

24. Parvan K, Zamanzadeh V, Hosseini FA (2012) Assessment of professional values among Iranian nursing students graduating in universities with different norms of educational services 1(2): 37-43.

25. Poorchangizi B, Borhani F, Abbaszadeh A, Mirzaee M, Farokhzadian (2019a) The importance of professional values from nursing students' perspective. BMC nursing 18(1): 26. 
26. Poorchangizi B, Borhani F, Abbaszadeh A, Mirzaee M, Farokhzadian J (2019b) Professional Values of Nurses and Nursing Students: a comparative study. BMC medical education 19(1): 438.

27. Poorchangizi B, Farokhzadian J, Abbaszadeh A, Mirzaee M, Borhani F (2017) The importance of professional values from clinical nurses' perspective in hospitals of a medical university in Iran. BMC medical Ethics 18(1): 20.

28. Schank MJ, Weis D (2000) Exploring commonality of professional values among nurse educators in the United States and England. Journal of Nursing Education 39(1): 41

29. Shafakhah M, Molazem Z, Khademi M, Sharif F (2018) Facilitators and inhibitors in developing professional values in nursing students. Nursing ethics 25(2): 153-164.

\section{ISSN: 2574-1241}

DOI: 10.26717/BJSTR.2021.38.006085

Nasser Abu-El-Noor. Biomed J Sci \& Tech Res

(C) (P) This work is licensed under Creative

Submission Link: https://biomedres.us/submit-manuscript.php
30. Sharif A, Afzal M, Hussain M, Gilani SA (2018) Professional Values Among Undergraduate Nursing Students. International Journal of Graduate Research and Review 5(1): 101-108.

31. Sibandze BT, Scafide KN (2018) Among nurses, how does education level impact professional values? A systematic review. International nursing review 65(1): 65-77.

32. Weis D, Schank MJ (1997) Toward building an international consensus in professional values. Nurse education today 17(5): 366-369.

33. Weis D, Schank MJ (2009) Development and psychometric evaluation of the nurse's professional values scale-revised. Journal of Nursing Measurement 17(3): 221-231.

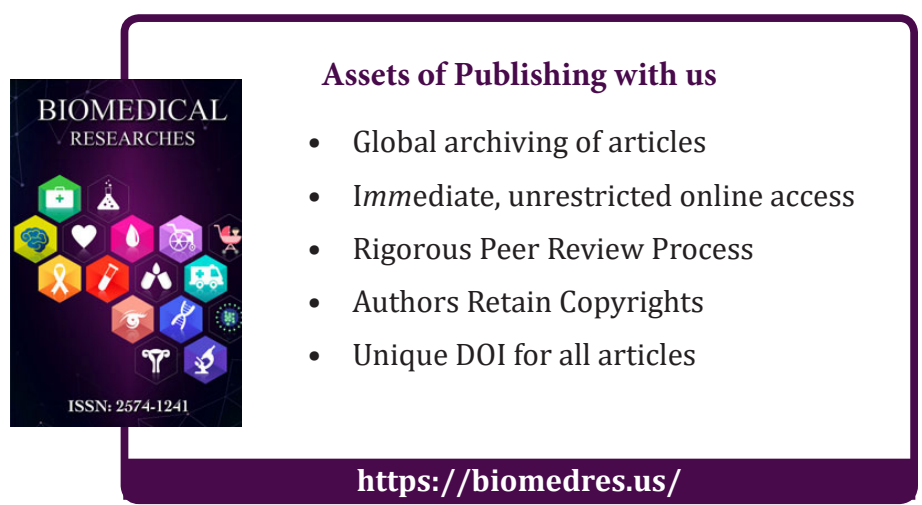

